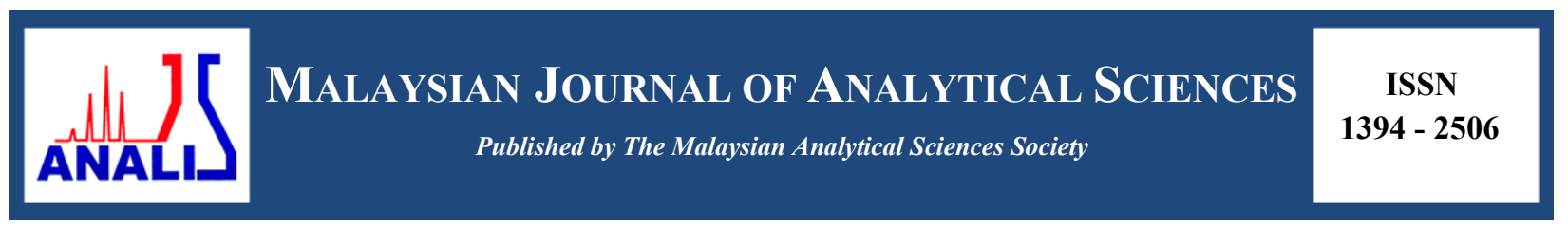

\title{
A REVIEW ON EXTRACTION SOLVENTS IN THE DISPERSIVE LIQUID- LIQUID MICROEXTRACTION
}

\author{
(Sebuah Ulasan Terhadap Pelarut Pengekstrakan dalam Pengekstrakan Mikro Cecair-Cecair \\ Serakan)
}

\author{
Tan Yeong Hwang ${ }^{1}$, Chai Mee Kin ${ }^{1}$, Wong Ling Shing ${ }^{2}$ \\ ${ }^{1}$ College of Engineering, \\ Universiti Tenaga Nasional, Jalan Ikram-Uniten, 43000 Kajang, Selangor, Malaysia \\ ${ }^{2}$ Faculty of Science, Technology, Engineering and Mathematics (FOSTEM), \\ INTI International University, Persiaran Perdana BBN, Putra Nilai, 71800 Nilai, Negeri Sembilan, Malaysia \\ *Corresponding author: yeonghwang_113@hotmail.com
}

Received: 26 August 2017; Accepted: 29 January 2018

\begin{abstract}
Dispersive liquid-liquid microextraction (DLLME) is a novel sample preparation technique that has higher level of extraction efficiency by means of relying on microvolumes of solvents. It has gained considerable attention from researchers owing to several advantages such as its simplicity, shorter extraction time, lower cost and higher enrichment factor. In conventional DLLME, chlorinated solvents are widely used as the extraction solvents. Notwithstanding, most of these solvents are reportedly toxic and environmentally-unfriendly. Many related studies in recent years have focused on the use of nontoxic or low toxic extraction solvents and better practical procedures, which have helped improve the extraction efficiency. The aim of this review is to discuss the development of low toxic extraction solvent used recently in the DLLME. The possible improvement of extraction solvent from the green analytical chemistry perspectives is also discussed.
\end{abstract}

Keywords: extraction solvents, dispersive liquid-liquid microextraction, green analytical chemistry

\begin{abstract}
Abstrak
Pengekstrakan mikro cecair-cecair serakan (DLLME) merupakan teknik penyediaan sampel novel yang mempunyai lebih tinggi kecekapan pengekstrakan dengan menggunakan mikroliter pelarut. Teknik ini telah mendapat perhatian daripada penyelidik kerana beberapa kelebihan seperti ringkas, masa pengekstrakan yang lebih pendek, kos yang lebih rendah dan faktor pengayaan yang lebih tinggi. Dalam DLLME konvensional, pelarut berklorin digunakan secara meluas sebagai pelarut pengekstrakan. Namun, kebanyakan pelarut ini dilaporkan toksik dan tidak mesra alam. Dalam tahun kebelakangan ini, banyak kajian yang berkaitan telah fokus kepada penggunaan pelarut pengekstrakan yang tidak bertoksik atau rendah toksik dan praktikal prosedur yang lebih baik telah meningkatkan kecekapan pengekstrakan. Tujuan kajian ini adalah untuk membincangkan perkembangan pelarut pengekstrakan rendah toksik yang digunakan dalam DLLME terkini. Penambahbaikan pelarut pengekstrakan dari perspektif kimia analisis hijau juga dibincangkan.
\end{abstract}

Kata kunci: pelarut pengekstrakan, pengekstrakan mikro cecair-cecair serakan, kimia analitik hijau 


\section{Introduction}

The step involving the sample preparation is the most important one in analytical process as most of the samples are not capable of being injected directly into the analytical instruments for analysis. The main aim of sample pretreatment is to both clean up and enrich the analytes of interest from the sample, and execute the analytes into forms that are considered suitable for instrument of analytical measurement [1].

As far as sample pre-treatment and separation are concerned, traditional methods for sample preparation such as liquid-liquid extraction (LLE) and solid-phase extraction (SPE) have mostly been used for many years. Nonetheless, some weaknesses were associated with these traditional methods such as the usage of large amount of organic solvents, which are toxic and environmentally-unfriendly, time-consuming and labour-intensive [2]. For this reason, many researchers have attempted towards better development of sample pre-treatment step that involves relatively lower solvent consumption, economic and rapid.

In the year of 2006, the dispersive liquid-liquid microextraction (DLLME), which is now one of the powerful sample pre-treatment techniques, was invented by Rezaee and his co-workers [3]. The advantages of DLLME method are inter alia simplicity, short extraction time, low cost, high enrichment factor, and high-recovery. As a result of such favourable characteristics, it has drawn considerable attention from analytical chemists. A significant number of research articles relating to DLLME having been published since its introduction bears testimony to the attention it has gained. Originally, the DLLME was established for preparation from water samples. Subsequently, it was developed for other matrices including food [4], soil [5], cosmetic products [6] and biological samples [7]. In relation to the types of analytes, they are not only limited to numerous organic compounds, but inorganic analytes were also successfully extracted from the sample using DLLME [8].

A comprehensive review of literature has pointed to many excellent reviews discussing the development and applications of DLLME [9-12]. Some of the reviews were found to summarise various strategies for improving dispersion liquid-liquid microextraction [13,14] and application with different analytical instruments [15, 16]. Notwithstanding such reviews, none of the reviews meticulously discussed the different types of extraction solvents used in DLLME. The present study therefore fills such a gap in the literature. Specifically, it presents the review of extraction solvents used in the conventional DLLME and modified DLLME. In addition, future trend of extraction solvents used in DLLME is also discussed from the perspective of green analytical chemistry.

\section{Principle of DLLME}

It has to be noted that the DLLME is based on the ternary solvent system, in which miniaturized volume of solvents are used. In a typical procedure, extraction solvent is mostly used to extract the analytes of interest from the samples. In the event of promoting the rapid transfer of analytes of interest from the samples, dispersion solvent is used. Upon injecting the mixture of extraction solvent and dispersion solvent into the sample solution, microdroplets of extraction solvent is rapidly dispersed into the aqueous sample and a cloudy solution is formed. As a large surface area is formed between extraction solvent and the aqueous sample in the cloudy solution, the transfer of analytes of interest to extraction phase is therefore rapid. As the extraction equilibrium is rapidly achieved, the extraction time is therefore relatively shorter. The mixture is then separated by centrifugation and the extraction solvent containing analytes of interest is collected by means of using microsyringe. This is followed by the identification of analytes in the extraction solvent, which can be performed using analytical instrument [3].

In order to obtain high extraction efficiency, several parameters have to be looked into. In such processes, the selection of appropriate extraction solvent is considered very important. In the DLLME, extraction solvent should have the following requirements: the extraction solvent is required to have low solubility with water and miscible with the dispersive solvent. In addition, it is also required to have the potential for extracting analytes of interest and suitable chromatographic behaviour. Besides, the extraction solvent must have different densities with the water so that it can be phase separated. In the conventional DLLME, the extraction solvent usually have relatively higher density than water. As a result, it is able to form sedimented phase in the bottom of the tube after phase separation [3]. Chlorinated solvents such as chloroform, chlorobenzene, carbon tetrachloride, and tetrachloroethylene are commonly selected as extraction solvent as they fulfil such requirements [17]. These chlorinated solvents show the advantages in DLLME such as producing high enrichment factor, short extraction time, ease of operation and high 
sensitivity [18-20]. However, these solvents are highly toxic. Most of them have low lethal dose and carcinogenic [21].

\section{Extraction solvents used in DLLME}

With the aim of minimizing the drawbacks associated with using chlorinated solvents, other types of solvents including heavy-density, low density and ionic liquid were introduced. Table 1 shows a summary of these extraction solvents. Heavy-density solvents including brominated and iodinated solvents have been introduced. The results revealed that extraction efficiencies of these solvents were comparable and higher than using the chlorinated solvents. Good sensitivity with relatively lower limit of detection was also obtained [22-26]. Compared to chlorinated solvents, some of the brominated and iodinated solvents have lower toxicity $[22,26,27]$. In addition, higher recovery efficiency with lower relative standard deviation can also be achieved by means of using only 1methyl-3-bromobutane as extraction solvent without having to rely on dispersive solvent, which is capable of reducing the use of organic solvent [28]. Nevertheless, not all brominated and iodinated solvents have lower toxicity. In this regard, some solvents such as 2-iodopropane [29] and 1, 2-dibromoethane [21] are as toxic as chlorinated solvents. Furthermore, there are only limited number of brominated or iodinated solvents with low toxicity [30].

Table 1. Summary of advantages and disadvantages of heavy-density, low density and ionic liquid

\begin{tabular}{lll}
\hline $\begin{array}{l}\text { Type of Extraction } \\
\text { Solvent }\end{array}$ & Advantages & Disadvantages \\
\hline $\begin{array}{l}\text { Heavy-density } \\
\text { solvent }\end{array}$ & $\begin{array}{l}\text { High extraction recovery } \\
\text { Some solvents can extract analytes without } \\
\text { dispersive solvents }\end{array}$ & $\begin{array}{l}\text { Limited choice of solvent. } \\
\text { Some solvents are as toxic as chlorinated } \\
\text { solvents. }\end{array}$ \\
Low-density solvent & $\begin{array}{l}\text { Higher extraction recovery } \\
\text { Lower toxicity extraction solvent } \\
\text { Choices of solvent are broader than heavy } \\
\text { density solvent }\end{array}$ & $\begin{array}{l}\text { Some require specially designed tools to } \\
\text { collect organic phase }\end{array}$ \\
& $\begin{array}{l}\text { Extract can be difficult to differentiate the } \\
\text { interphase between the floating organic } \\
\text { phase and the aqueous phase } \\
\text { Comethods do not required } \\
\text { centrifugation }\end{array}$ & $\begin{array}{l}\text { Choice of solvents for DLLME-SFO is } \\
\text { limited }\end{array}$ \\
& $\begin{array}{l}\text { Lower melting point, lower vapor pressure, } \\
\text { higher thermal stability and good solubility } \\
\text { in organic and inorganic compounds }\end{array}$ & $\begin{array}{l}\text { Not suitable for analysis with GC } \\
\text { Toxicity to environment is not well } \\
\text { understood }\end{array}$ \\
& $\begin{array}{l}\text { Higher extraction recovery and sensitivity } \\
\text { Choices of solvent are broader than low- } \\
\text { density and high-density solvents }\end{array}$ & \\
\hline
\end{tabular}

*DLLME-SFO: Dispersive liquid liquid microextraction based on solidification of floating drop

GC: gas chromatography

Low-density solvents were used recently as extraction solvent in DLLME. The choice of lower-density organic solvent is more popular than high-density solvents [31]. The low-density solvents such as n-hexane [30], toluene [32], 2-ethyl-1-hexanol [31], 1-heptanol [34], 1-octanol [35], isooctane [36], and 1-dodecanol [37] and 1-undecanol [38] have been used as extraction solvents in low-density solvents (LDS) DLLME. In addition, they have been proven to possess low LOD and LOQ, high recovery and higher linearity. Unlike in the conventional DLLME, the low-density solvents do not sediment at the bottom of the tubes as the low-density extraction solvent floats on the top of the aqueous phase after phase separation is carried out. The floated extraction solvent is much easier to collect and the extract is cleaner since any matrix components will be sedimented at the bottom of the extraction vessel [4]. Therefore, a good chromatogram can be easily achieved. It is also worthy of note that some methods do 
not require centrifugation for phase separation and thus extraction time is relatively shorter. Low-density extraction solvent droplets float on the surface of the aqueous phase after the samples and solvents are mixed and shaken [35]. Then, the floating extraction phase was collected by means of employing different techniques. This method is useful for preventing analytes from being degraded by excessive centrifugation or ultrasonic energy [39]. However, to draw off the floating solvents, some required the use of specially designed devices [40].

Leong \& Huang [41] and Xu et al. [42] developed the new DLLME method based on solidification of a floating organic drop (DLLME-SFO). Specifically, the mixture of low-density extraction solvent and dispersive solvent are injected into aqueous samples and as a result, a cloudy solution is formed. The mixture is then centrifuged and placed in the ice bath to solidify the floated extraction solvent. Following the solidification stage, the solidified solvent is taken by spatula and melted prior to sending it for analysis. In DLLME-SFO, extraction solvent must fulfil several requirements, namely low melting point below room temperature, low solubility in water, lower density than water, and high affinity towards analytes of interest and compatible for instrument analysis. Good extraction efficiencies such as low LOQ, LOD and high recovery were successfully obtained by means of using the DLLME-SFO [37, 43-45]. In comparison with the conventional DLLME, this method uses low-toxic extraction solvents. The drawbacks of this method are limited to the solvent selected, which must have low melting point of below room temperature. This method may not be considered as suitable for use if the laboratory is not air conditioned and located in warm climate [13]. Apart from that, spatula is used for transfer solidified solvent, which may result in the loss of analytes. Guiñez and his teammates [45] tried using Hamilton syringe to collect floating or solidified extraction solvent but the efficiency was low since the interphase between the floating organic phase and the aqueous phase was rather hard to differentiate. Besides, Nojavan and his colleagues [46] indicated that highdensity solvents had revealed better performance and reproducibility than lower-density solvents in extraction of seven basic pharmaceutical compounds.

Room temperature ionic liquids or ionic liquids (ILs, not all ILs are room temperature ILs.) are one of the extraction solvents that have been widely discussed in the literature. ILs are the salts that are made of substituted organic cation with an organic or inorganic anion that exist in liquid state at room temperature [47]. They possess outstanding physical properties such as low melting point, low vapour pressure, high thermal stability and good solubility in organic and inorganic compounds. As ILs are non-flammable and non-volatile, they are therefore classified as green solvent $[9,48]$. Quite a number of studies related to IL-DLLME and a few review pieces have been published since IL-DLLME was first introduced in the year of 2008 [9, 47, 48]. Based on cation segment, ILs can be categorized into four types, which are alkylammonium-based, dialkylimidazolium-based, phosphoniumbased and N-alkylpyridinium-based [49]. Most of the works have been found to have used dialkylimidazoliumbased ILs as extraction solvents. In this regard, Hu et al. [50] employed three different dialkylimidazolium-based ILs as extraction solvent for determination of urinary 3-hydroxybenzo [a] pyrene. The recovery was found to be much higher than chlorinated solvents. IL-DLLME revealed excellent sensitivity with relatively lower LOD within a range of $\mathrm{pg} / \mathrm{mL}[50,51]$ or $\mathrm{ng} / \mathrm{mL}$ [52-54] was obtained. Moreover, the types of ionic liquid are broader as many kinds of cations and anions can be combined [55]. By means of changing the structure and interaction of ions, their chemical and physical properties can vary and thus, ILs can be designed to exhibit target-selective [47]. Nonetheless, ILs have several drawbacks. Low volatility of ILs make them not suitable for gas chromatography. Hence, most IL-DLLME reported in related studies were coupled with high performance liquid chromatography (HPLC). However, ILs will be retained in the column or injector, which can result in distorted chromatograms [56, 57]. In order to overcome such problems, special design of injectors are required such as the combination of programmed temperature vaporization injector and thermal desorption unit, which can directly inject the analytes and prevent the entering of ILs into GC system [51].

\section{Future trend based on green analytical chemistry}

As a result of the limitless and almost never-ending human activities, there have been growing concerns about the potential negative influences on the environment. The side effects of the environment must be taken into consideration in the chemistry activities. The ideas of "green analytical chemistry" was originally proposed in the year of 2008 [58]. Green analytical chemistry can be applied in many forms, one of the segments is the reduction of the amount and toxicity of the solvents and reagent used. Thus, high toxicity solvents especially halogenated solvents have to be avoided from being used in sample preparation. Some interesting alternatives such as ILs, agro- 
solvents and lipid structures could be greener solution for replacement of high toxicity solvents [59]. Nevertheless, their strengths, weaknesses, threats to the environment and compatibility to the analytical instruments should be explicitly identified due to the fact that their detrimental effects are not well understood.

The concept of three Rs (reduce, replace, recycle) has often been mentioned in the green analytical chemistry [60]. The reuse of chemicals or materials in process with minimum interferences from extraction efficiency is considered necessary. For instance, Wang and colleagues [61] applied such concepts in their attempts to extract three endocrine disrupting compounds from food packaging. Specifically, IL used as extraction solvent, was successfully recovered by modifying the $\mathrm{pH}$ and it can be reused three times without any significant loss of extraction efficiencies. In addition, Sheikhian and Shirafkan [62] also successfully separated ILs from analytes by changing pH and reused ILs at least four times. These methods are capable of minimizing the cost of extraction solvents and the environment and safety issues. In addition, recycle of ILs can help prevent the problem of ILs remaining in the column of HPLC. Hence, future works may have to zoom in on identifying ways to recycle and reuse the solvents.

One of the growing trends in analytical chemistry is the automation of extraction and analytical procedures. Automation is capable of minimizing the operator risks, waste generation, energy and solvent consumption [59]. In this regard, many innovative ideas for automated DLLME including automated agitation-assisted demulsification DLLME [63], effervescence assisted DLLME [64] and DLLME-switchable polarity dispersive solvent (DLLMESPDS) [65] have over the years been introduced. The former method used agitation for the phase separation and the whole automated process requires only a total of $160 \mu \mathrm{L}$ of solvents. The latter two approaches are automated and they have also excluded the negative impact of dispersive solvents on the solubility of analytes in aqueous sample. However, DLLME-SPDS has some limitations; it is only able to extract analytes in neutral and alkaline medium. Other automated techniques including flow, batch, flow-batch and in-syringe modes were also reported in the literature [66].

\section{Conclusion}

DLLME is considered as a powerful sample preparation for extraction of analytes from aqueous samples. It is worthy of note that the selection of appropriate extraction solvent is a critical parameter with the aim of acquiring a good extraction efficiency. Several types of extraction solvents such as the heavy-density solvents, low-density solvent and ionic liquids are discussed in the paper. In addition, the future trend for development of extraction solvents based on green chemistry was also intensively discussed. Overall, the exploitation of new extraction solvents and improvement of extraction performance in DLLME based on green analytical chemistry can be the main focus in future.

\section{Acknowledgement}

The authors would like to express special thanks to the Ministry of Higher Education of Malaysia ''Fundamental Research Grand no. "FRGS/1/2016/STG01/UNITEN/02/1" for the financial supports, and Institute of Sustainable Energy of UNITEN for the laboratory analysis.

\section{References}

1. Saraji, M. and Boroujeni, M. K. (2013). Recent developments in dispersive liquid-liquid microextraction. Analytical and Bioanalytical Chemistry, 406(8): 2027 - 2066.

2. Sarafraz-Yazdi, A. and Amiri, A. (2010). Liquid-phase microextraction. Trends in Analytical Chemistry, 29(1): $1-14$.

3. Rezaee, M., Assadi, Y., Hosseini, M. R. M., Aghaee, E., Ahmadi, F. and Berijani, S. (2006). Determination of organic compounds in water using dispersive liquid-liquid microextraction. Journal of Chromatography A, 1116(1): $1-9$.

4. Habibi, H., Mohammadi, A. and Kamankesh, M. (2017). Application and optimization of dispersive liquidliquid microextraction coupled with high-performance liquid chromatography for sensitive determination of furfural and hydroxymethyl furfural in jarred and canned baby-foods. Nutrition and Food Sciences Research, 4(1): $25-32$. 
5. Pastor-Belda, M., Garrido, I., Campillo, N., Viñasa, P., Hellín, P., Flores, P. and Fenoll, J. (2015). Dispersive liquid-liquid microextraction for the determination of new generation pesticides in soils by liquid chromatography and tandem mass spectrometry. Journal of Chromatography A, 1394: 1 - 8.

6. Chisvert, A., Benedé, J. L., Peiró, M., Pedrón, I. and Salvador, A. (2017). Determination of Nnitrosodiethanolamine in cosmetic products by reversed-phase dispersive liquid-liquid microextraction followed by liquid chromatography. Talanta, 166: $81-86$.

7. Asghari, A., Saffarzadeh, Z., Bazregar, M., Rajabi, M. and Boutorabi, L. (2017). Low-toxic air-agitated liquidliquid microextraction using a solidifiable organic solvent followed by gas chromatography for analysis of amitriptyline and imipramine in human plasma and wastewater samples. Microchemical Journal, 130: 122 128.

8. Liang, P. and Sang, H. B. (2008). Determination of trace lead in biological and water samples with dispersive liquid-liquid microextraction preconcentration. Analytical Biochemistry, 380(1): $21-25$.

9. Zang, H. X. Wu, Q. H., Zhang, M. Y., Xi, G. H. and Zhi, W. (2009). Developments of dispersive liquid-liquid microextraction technique. Chinese Journal of Analytical Chemistry, 37(2): 161 - 168.

10. Zgoła-Grzeskowiak, A. and Grzeskowiak, T. (2011). Dispersive liquid-liquid microextraction. Trends in Analytical Chemistry, 30(9): $1382-1399$.

11. Viñas, P., Campillo, N., López-García, I. and Hernández-Córdoba, M. (2013). Dispersive liquid-liquid microextraction in food analysis: A critical review. Analytical and Bioanalytical Chemistry, 406(8): 2067 2099.

12. Campillo, N., Viñas, P., Šandrejová, J. and Andruch, V. (2016). Ten years of dispersive liquid-liquid microextraction and derived techniques. Applied Spectroscopy Reviews, 52(4): 267 - 415.

13. Leong, M. I., Fuh, M. R. and Huang, S. D. (2014). Beyond dispersive liquid-liquid microextraction. Journal of Chromatography A, 1335: 2 - 14 .

14. Li, M. J. Zhang, H. Y., Liu, X. Z., Chui, C. Y. and Shi, Z. H. (2015). Progress of extraction solvent dispersion strategies for dispersive liquid-liquid microextraction. Chinese Journal of Analytical Chemistry, 43(8): 1231 1240 .

15. Al-Saidi, H. M. and Emara, A. A. A. (2014). The recent developments in dispersive liquid-liquid microextraction for preconcentration and determination of inorganic analytes. Journal of Saudi Chemical Society, 18(6): $745-761$.

16. Ahmad, W., Al-Sibaai, A. A., Bashammakh, A. S., Alwael, H. and El-Shahawi, M. S. (2015). Recent advances in dispersive liquid-liquid microextraction for pesticide analysis. Trends in Analytical Chemistry, 72: 181 - 192.

17. Alcantara, G. S. K., Calixto, L. A., de Moraes, L. A. B., Queiroz, R. H. C., de Oliveira, A. R. M. and de Gaitani, C. M. (2016). Determination of levetiracetam in human plasma by dispersive liquid-liquid microextraction followed by gas chromatography-mass spectrometry. Journal of Analytical Methods in Chemistry, 2016: 1-12.

18. Tobiszewski, M., Bigus, P. and Namiesnik, J. (2014). Determination of parent and methylated polycyclic aromatic hydrocarbons in water samples by dispersive liquid-liquid microextraction two-dimensional gas chromatography-time-of-flight mass spectrometry. Analytical Method, 6(17): 6678 - 6687.

19. Liu, J. Y., Lu, W. H. Liu, H. T., Wu, X. Q., Li, J. H. and Chen, L. X. (2016). Dispersive liquidliquidmicroextraction for four phenolic environmental estrogens in water samples followed by determination using capillary electrophoresis. Electrophoresis, 37(19): $2502-2508$.

20. Larki, A. (2017). A novel application of carbon dots for colorimetric determination of fenitrothion insecticide based on the microextraction method. Spectrochimica Acta Part A: Molecular and Biomolecular Spectroscopy, 173: $1-5$.

21. U. S. National Library of Medicine (2016). Hazardous Substances Data Bank. https://toxnet.nlm.nih.gov/ newtoxnet/hsdb.htm. [Access online 2 July 2017].

22. $\mathrm{Hu}, \mathrm{X} . \mathrm{Z}$., $\mathrm{Wu}$, J. H. and Feng, Y. Q. (2010). Molecular complex-based dispersive liquid-liquid microextraction: Analysis of polar compounds in aqueous solution. Journal of Chromatography A, 1217(45): $7010-7016$.

23. Farajzadeh, M. A. Djozan, D., Afshar, M. R. and Norouzi, J. (2012). Determination of phthalate esters in cow milk samples using dispersive liquid-liquid microextraction coupled with gas chromatography followed by flame ionization and mass spectrometric detection. Journal of Separation Science, 35(5-6): 742 - 749. 
24. Pena, M. T., Vecino-Bello, X., Casais, M. C., Mejuto, M. C. and Cela, R. (2012). Optimization of a dispersive liquid-liquid microextraction method for the analysis of benzotriazoles and benzothiazoles in water samples. Analytical and Bioanalytical Chemistry, 402(4): 1679 - 1695.

25. Emídio, E. S., da Silva, C. P. and de Marchi, M. R. R. (2015). Determination of estrogenic mycotoxins in environmental water samples by low-toxicity dispersive liquid-liquid microextraction and liquid chromatography-tandem mass spectrometry. Journal of Chromatography A: 1391(1): $1-8$.

26. Peng, G. L. Lu, Y. He, Q., Mmereki, D., Zhou, G. M., Chen, J. H. and Tang, X. H. (2016). Dispersive liquidliquid microextraction using low-toxic solvent for the determination of heavy metals in water samples by inductively coupled plasma-mass spectrometry. Journal of AOAC International, 99(1): 260 - 266.

27. Leong, M. I., Chang, C. C., Fuh, M. R. and Huang, S. D. (2010). Low toxic dispersive liquid-liquid microextraction using halosolvents for extraction of polycyclic aromatic hydrocarbons in water samples. Journal of Chromatography A, 1217(34): 5455 - 5461.

28. Chai, M. K., Premla, D. C. and Wong, L. S. (2016). Modified dispersive liquid-liquid microextraction using green solvent for determination of polycyclic aromatic hydrocarbons (PAHs) in vegetable samples. Malaysian Journal of Analytical Sciences, 20(1): $14-20$.

29. Chemical Book (2016). http://www.chemicalbook.com/CAS_75-30-9.htm. [Access online 2 July 2017].

30. Guo, L. and Lee, H. K. (2011). Low-density solvent-based solvent demulsification dispersive liquid-liquid microextraction for the fast determination of trace levels of sixteen priority polycyclic aromatic hydrocarbons in environmental water samples. Journal of Chromatography A, 1218(31): 5040 - 5046.

31. Chen, X. C., You, X. W., Liu, F. M. and Zhang, X. (2015). Low-density solvent based vortex-assisted surfactant enhanced emulsification microextraction with a home-made extraction device for the determination of four herbicide residues in river water. Analytical Method, 7(22): 9513 - 9519.

32. Barrett, C. A., Orban, D. A., Seebeck, S. E., Lowe, L. E. and Owens, J. E. (2015). Development of a lowdensity-solvent dispersive liquid-liquid microextraction with gas chromatography and mass spectrometry method for the quantitation of tetrabromobisphenol-A from dust. Journal of Separation Science, 38: 2500 2509.

33. Fatemi, M. H., Hadjmohammadi, M. E. and Shakeri, P. (2014). Evaluation of alcoholic-assisted dispersive liquid-liquid microextraction of bisphenol $\mathrm{A}$ in water samples using an experimental design. Acta Chromatographica, 26 (3): $401-412$.

34. Aghamohammadi, M., Shahdousti, P. and Harooni, B. (2016). Ultrasound-assisted emulsification microextraction followed by gas chromatography-flame ionization detection for urinary methylmalonic acid determination. Microchemical Journal, 124: 188 - 194.

35. Çabuk, H. and Köktürk, M. (2013). Low density solvent-based dispersive liquid-liquid microextraction for the determination of synthetic antioxidants in beverages by high-performance liquid chromatography. The Scientific World Journal, 2013: $1-8$.

36. Bai, X. Z. Zhang, T., Li, H. P. and Yang, Z. G. (2016). Simultaneous dispersive liquid-liquid microextraction based on a low-density solvent and derivatization followed by gas chromatography for the simultaneous determination of chloroanisoles and the precursor 2,4,6-trichlorophenol in water samples. Journal of Separation Science, 39: $2146-2155$.

37. Xu, H., Ding, Z. Q., Lv, L. L., Song, D. D. and Feng, Y. Q. (2009). A novel dispersive liquid-liquid microextraction based on solidification of floating organic droplet method for determination of polycyclic aromatic hydrocarbons in aqueous samples. Analytica Chimica Acta, 636: 28 - 33.

38. Rezaee, M., Yamini, Y., Khanchi, A., Faraji, M. and Saleh, A. (2010). A simple and rapid new dispersive liquidliquid microextraction based on solidification of floating organic drop combined with inductively coupled plasma-optical emission spectrometry for preconcentration and determination of aluminium in water samples. Journal of Hazardous Materials, 178: 766 - 770.

39. Peng, G. L., He, Q., Mmereki, D., Zhou, G. M., Pan, W. L., Gu, L., Fan, L. L. and Mao, Y. F. (2015). Vortexassisted liquid-liquid microextraction using a low-toxicity solvent for the determination of five organophosphorus pesticides in water samples by high-performance liquid chromatography. Journal of Separation Science, 38 (20): 3487 - 3493.

40. Kocúrová, L., Balogh, I. S., Šandrejová, J. and Andruch, V. (2012). Recent advances in dispersive liquid-liquid microextraction using organic solvents lighter than water. A review. Microchemical Journal, 102: 11 - 17. 
41. Leong, M. I. and Huang, S. D. (2008). Dispersive liquid-liquid microextraction method based on solidification of floating organic drop combined with gas chromatography with electron-capture or mass spectrometry detection. Journal of Chromatography A, 1211: 8 - 12.

42. Xu, H., Ding, Z. Q., Lv, L. L., Song, D. D. and Feng, Y. Q. (2009). A novel dispersive liquid-liquid microextraction based on solidification of floating organic droplet method for determination of polycyclic aromatic hydrocarbons in aqueous samples. Analytica Chimica Acta, 636(1): 28 - 33.

43. Asadollahi, T., Dadfarnia, S., Shabani, A. M. H. and Amirkavei, M. (2015). Separation/preconcentration and determination of quercetin in food samples by dispersive liquid-liquid microextraction based on solidification of floating organic drop -flow injection spectrophotometry. Journal of Food Science and Technology, 52(2): $1103-1109$.

44. Bolzan, C. M. Caldas, S. S., Guimarães, B. S., and Primel, E. G. (2016). Dispersive liquid-liquid microextraction based on solidification of floating organic droplet for the determination of triazine and triazoles in mineral water samples. Journal of Separation Science, 39(17): 3410 - 3417.

45. Guiñez, M., Martinez, L. D., Fernandez, L. and Cerutti, S. (2017). Dispersive liquid-liquid microextraction based on solidification of floating organic drop and fluorescence detection for the determination of nitrated polycyclic aromatic hydrocarbons in aqueous samples. Microchemical Journal, 131: $1-8$.

46. Nojavan, S., Gorji, T., Davarani, S. S. H. and Morteza-Najarian, A. (2014). Solvent selection in ultrasonicassisted emulsification microextraction: Comparison between high- and low-density solvents by means of novel type of extraction vessel. Analytica Chimica Acta, 838: 51 - 57.

47. Ho, T. D., Zhang, C., Hantao, L. W., and Anderson, J. L. (2014). Ionic liquids in analytical chemistry: Fundamentals, advances, and perspectives. Analytical Chemistry, 86: $262-285$.

48. Vekariya, R. L. (2017). A review of ionic liquids: Applications towards catalytic organic transformations. Journal of Molecular Liquids, 227: 44 - 60.

49. Ghandi, K. (2014). A review of ionic liquids, their limits and applications. Green and Sustainable Chemistry, 4: $44-53$.

50. Hu, H., Liu, B. Z., Yang, J., Lin, Z. M. and Gan, W. (2016). Sensitive determination of trace urinary 3hydroxybenzo[a]pyrene using ionic liquids-based dispersive liquid-liquid microextraction followed by chemical derivatization and high performance liquid chromatography-high resolution tandem mass spectrometry. Journal of Chromatography B, 1027: 200 - 206.

51. Cacho, J. I., Campillo, N., Viñas, P. and Hernández-Córdoba, M. (2016). Improved sensitivity gas chromatography-mass spectrometry determination of parabens in waters using ionic liquids. Talanta, 146: 568 -574 .

52. Peng, B., Zhang, J. H., Wu, C. H., Li, S. Q., Li, Y. B., Gao, H. X., Lu R. H. and Zhou W. F. (2014). Use of ionic liquid-based dispersive liquid-liquid microextraction and high-performance liquid chromatography to detect formaldehyde in air, water, and soil samples. Journal of Liquid Chromatography \& Related Technologies, 37(6): $815-828$.

53. Gong, A. Q. and Zhu, X. S. (2015). Dispersive solvent-free ultrasound-assisted ionic liquid dispersive liquidliquid microextraction coupled with HPLC for determination of ulipristal acetate. Talanta, 131: 603 - 608 .

54. Albishri, H. M., Aldawsari, H. A. M. and El-Hady, D. A. (2016). Ultrasound-assisted temperature-controlled ionic liquid dispersive liquid phase microextraction combined with reversed phase liquid chromatography for determination of organophosphorus pesticides in water samples. Electrophoresis, 37 (39): $2462-2469$.

55. Trujillo-Rodríguez M. J., Rocío-Bautista, P., Pino, V. and Afonso, A. M. (2013). Ionic liquids in dispersive liquid-liquid microextraction. Trends in Analytical Chemistry, 51: 87 - 106.

56. Poole, C. F. and Poole, S. K. (2010). Extraction of organic compounds with room temperature ionic liquids. Journal of Chromatography A, 1217 (16): 2268 - 2286.

57. Ma, X. G., Huang, M. H., Li, Z. H. and Wu, J. M. (2011). Hollow fiber supported liquid-phase microextraction using ionic liquid as extractant for preconcentration of benzene, toluene, ethylbenzene and xylenes from water sample with gas chromatography-hydrogen flame ionization detection. Journal of Hazardous Materials, 194: $24-29$.

58. Armenta, S. Garrigues, S. and de la Guardia, M. (2008). Green analytical chemistry. Trends in Analytical Chemistry, 27(6): $497-511$.

59. Armenta, S., Garrigues, S. and de la Guardia, M. (2015). The role of green extraction techniques in Green analytical chemistry. Trends in Analytical Chemistry, 71:2 -8. 
60. Welch, C. J. Wu, N. J. M., Biba, M., Hartman, R., Brkovic, T., Gong. X. Y., Helmy, R., Schafer, W., Cuff, J., Pirzada, Z. and Zhou, L. L. (2010). Greening analytical chromatography. Trends in Analytical Chemistry, 29 (7): $667-680$.

61. Wang, L. L., Zhang, D. F., Xu, X. and Zhang, L. (2016). Application of ionic liquid-based dispersive liquid phase microextraction for highly sensitive simultaneous determination of three endocrine disrupting compounds in food packaging. Food Chemistry, 197: 754-760.

62. Sheikhian, L. and Shirafkan, M. (2016). Temperature-assisted ionic liquid-based dispersive liquid-liquid microextraction with following back-extraction for HPLC/UV-Vis determination of 3-indole acetic acid in pea plants. Journal of Iranian Chemical Society, 13(5): 903 - 911.

63. Guo, L., Chia, S. S. and Lee, H. K. (2016). Automated agitation-assisted demulsification dispersive liquidliquid microextraction. Analytical Chemistry, 88 (5): 2548 - 2552.

64. Medinskaia, K., Vakh, C., Aseeva, D., Andruch, V., Moskvin, L. and Bulatov, A. (2016). A fully automated effervescence assisted dispersive liquid-liquid microextraction based on a stepwise injection system. Determination of antipyrine in saliva samples. Analytica Chimica Acta, 902: 129 - 134.

65. Timofeeva, I., Timofeev, S., Moskvin, L. and Bulatov, A. (2017). A dispersive liquid-liquid microextraction using a switchable polarity dispersive solvent. Automated HPLC-FLD determination of ofloxacin in chicken meat. Analytica Chimica Acta, 949: 35 - 42.

66. Alexovič, M., Horstkotte, N., Šrámková, I. Solich, P. and Sabo, S. (2017). Automation of dispersive liquidliquid microextraction and related techniques. Approaches based on flow, batch, flowbatch and in-syringe modes. Trends in Analytical Chemistry, 86: 39 - 55. 